\title{
Review of John McMillan, The Methods of Bioethics: An Essay in Meta-Bioethics
}

\author{
Reviewed byJonathan Lewis
}

\section{QUERY SHEET}

This page lists questions we have about your paper. The numbers displayed at left are hyperlinked to the location of the query in your paper.

The title and author names are listed on this sheet as they will be published, both on your paper and on the Table of Contents. Please review and ensure the information is correct and advise us if any changes need to be made. In addition, please review your paper as a whole for typographical and essential corrections.

Your PDF proof has been enabled so that you can comment on the proof directly using Adobe Acrobat. For further information on marking corrections using Acrobat, please visit http://journalauthors.tandf.co.uk/production/acrobat.asp; https://authorservices.taylorandfrancis.com/how-to-correct-proofs-with-adobe/

The CrossRef database (www.crossref.org/) has been used to validate the references.

\section{AUTHOR QUERIES}

Q1 The ORCID details of the authors have been validated against ORCID registry. please check the ORCID ID details of the authors. 
John McMillan begins his new book by reflecting on his introduction to bioethics in the 1990s. Having been nurtured on an intellectual diet of formal semantics of modal logics, meta-ethics, and theories about the nature of mental states, he recalls how surprised he was to find the bioethical literature so preoccupied with theory. Although McMillan recognizes that moral theory has its place, he suggests that by setting bioethics up as a discipline whose predominant issues are to do with theory, not only are students insulated from the broadness of its scope and the diversity of its methods, but the subject comes across as largely inaccessible to those without some formal training in normative ethics and of limited practical significance to those dealing with concrete issues.

Fortunately, McMillan avers, for those new to bioethics, there is a better way to get started. Inspired by figures who were active during the early days of the discipline, including Margaret Battin, Dan Callahan, Alastair Campbell, and Jonathan Glover, he seeks to develop a multifaceted, argument-centered approach to real ethical issues that is both accessible and applicable irrespective of one's disciplinary background.

In part one, McMillan establishes the nature of "good bioethics." Drawing upon Alastair Campbell's notions of "no special pleading" and "engagement with experience," McMillan calls into question more traditional approaches to bioethics that privilege specific theoretical positions such as utilitarianism, virtue ethics, principlism, and theology at the expense of interdisciplinary engagement with moral phenomena of complex situations. He argues that the essential aims, concerns, and features of bioethics involve bringing moral reason to bear on practical and pressing issues in order to generate reflective, normative arguments that meet the needs of patients, practitioners, and policymakers. In short, "bioethics has to connect with the experiences of those impacted by, and making, decisions in health care" (36); it must be practically normative "in the sense of attempting to improve some aspect of the world" (40). Conceived in this way, bioethics is not just a scholarly discipline that manifests in publications, conference presentations, and seminars (15). For McMillan, there is a vital "moral consequentialist" dimension to bioethics in the sense that it involves contributions to public policy and biomedical case consultation (11-16). Consequently, he argues that bioethics cannot be identified with law, philosophical bioethics, medical ethics, applied ethics, or empirical ethics. Instead, it requires empirically grounded, philosophically inspired argumentation (chaps. 2-3).

In part two, McMillan attempts to exorcize the "specters of bioethics": theory and the fact/value distinction. In terms of the former, he is concerned with the privileged status given to normative moral theories. Referring to Tom L. Beauchamp and James F. Childress's work in the 1970s, McMillan notes that although it was helpful to have a moral framework that could simultaneously highlight ethical duties, justify moral beliefs, and provide some coherence and uniformity to the field of bioethics, such an approach stifled careful reflection about real issues. He claims that principle-based methods (as well as those theories that developed in response to consequentialist, deontological, and pluralist principle approaches) cannot lead to the formulation of "reasoned convictions about moral problems" (53).

McMillan refers to theory-driven approaches as examples of the "ethics sausage machine" (53-63). The point is that "a theoretically driven approach to bioethics will mince a variety of background considerations and issues into a familiar recommendation that is so systematic that, unless we buy the whole machine, we will not want to eat the sausage" (54). Focusing his critique on Peter Singer's utilitarianism, Pope Paul VI's Humanae Vitae, neoKantianism, and certain approaches in medical sociology, McMillan claims that theory-driven approaches include ingredients (in the form of premises) that prove to be unpalatable to those dealing with concrete bioethical issues in an interdisciplinary and undogmatic way. 
In chapter five, McMillan argues that bioethics is still haunted by the specter of the fact/value distinction. With the Humean idea that ethical claims cannot be identified with anything "out there" in the world in the way that scientific facts purportedly can, it seems that what we take to be right or wrong cannot be empirically verified. As a result, some still believe that ethical claims are not amenable to reason. On the one hand, McMillan suggests that the fact/value distinction is a helpful reminder that we must not make unwarranted inferences from descriptive premises to normative conclusions (73-78). On the other hand, he agrees with the majority of metaethicists who argue that just because ethical claims may not be true in the same way as natural facts, that does not mean that the normative language that distinctively figures in practical reason is epistemically defunct, nor does it mean that ethical claims cannot be assessed as legitimate or illegitimate. For McMillan, the key to assessing legitimacy is to be attentive to argumentative strategies and the evidence used to inform these arguments.

In the most substantial section of the book, McMillan offers a detailed account of the methods that constitute "good bioethics." This "empirical, Socratic bioethics" combines cogent arguments, empirical evidence, and awareness of one's epistemic fallibilities (chap. 6). Vital to the Socratic dimension of McMillan's approach is the need to address "what if?" questions concerning the different possibilities of concrete situations and the clarification, introduction, and testing of morally pertinent concepts (chaps. 8-10). As a starting point, we require empirical knowledge of "current issues and developments" (94). For example, in the case of noninvasive prenatal testing (NIPT), McMillan suggests that we begin by identifying and understanding the phenomena that can be tested, the companies involved, the false positive rates, and the discussions with women who wish to sign up for it. Subsequently, our job is to subject this evidence to critical appraisal. The final stage uses our appraisal of the evidence in order to construct cogent, factually premised arguments (chap. 7).

Although McMillan manages to present his account of "good bioethics" in the first six chapters, the remaining chapters will be invaluable to those who may not be acquainted with the type of argument-centered, factually premised approach that he is advocating. In chapter seven, he explains how to construct cogent arguments. Chapter eight addresses six different approaches to speculative reason involving both real and imagined situations. Finally, in chapters nine and ten, McMillan discusses the ways in which "good bioethics" requires us to "draw distinctions." The point is that concepts such as "euthanasia," "medical futility," "sanctity of life," "medical treatment," and "medicine" can have different senses with different moral implications. "Good bioethics" generates a requirement to avoid ambiguity in the ethical concepts that figure in moral arguments. To that end, a vital concern is not only to clarify the concepts that are used, make explicit important moral distinctions between concepts, and assess whether a concept does the normative work that it needs to, but introduce concepts and conceptual distinctions that have been suitably clarified in other disciplines.

Bearing in mind the amount of space dedicated to speculative reason and conceptual analysis, McMillan's monograph posits an account of "good bioethics" that, although empirically aware, is situated more toward the philosophical end of the methodological spectrum. As a result, nonphilosophers might find it difficult to fully comprehend the ways in which their respective disciplines can contribute to such an argument-centered, factually premised account. After all, it is not just philosophy that suffers from problems internal to the discipline. Questions concerning the necessary conditions for something to count as evidence, the validity of causal inferences, and the practicalities of justifiably making normative claims based on nonnormative facts have resulted in well-reasoned disagreement in all areas of the medical, behavioral, and social sciences. That said, McMillan includes a number of detailed examples in order to demonstrate how his approach can work in an interdisciplinary context. He brings both his negative and positive accounts of bioethics to bear on an impressively broad range of concrete issues concerning abortion, anencephalic infants, castration of sex offenders, euthanasia and aid-in-dying, growth attenuation therapy, noninvasive prenatal testing, reproductive technologies, persistent vegetative states, and artificial nutrition and hydration. Consequently, those looking to engage with bioethics from traditionally nonphilosophical fields should, with relative ease, be able to identify ways in which their own expertise and preferred empirical methods can operate within the Socratic dimension of McMillan's approach.

By exploring the nature of bioethics and attempting to answer the question "what is 'good bioethics?,'" McMillan presents an innovative, historically aware, and zeitgeist-capturing manifesto for contemporary bioethics. Not only does he consolidate a striking number of detailed discussions of his own work and that of leading figures in both bioethics and ethics in general, but he manages to incorporate pertinent real-world issues in health care policy and practice. Overall, this book serves not only as a fresh foundation on which bioethicists from all disciplines can build, but as a provocative challenge to traditional theory-laden ways of "doing bioethics."

\section{ORCID}

Jonathan LewisReviewed by (D) http://orcid.org/0000-00018342-1051 